In conclusion, to protect HCWs caring for COVID-19 patients during mechanical ventilation, the of using an HME or a dual-limb heated ventilator circuit with minimal condensate production should be considered. The selection should made according to the patient's minute ventilation and the amount and properties of secretions to provide adequate inhaled gas temperature and humidity. To protect HCWs, a pleated hydrophobic filter with at least $99.97 \%$ filtration efficiency should be placed in the expiratory limb of the ventilator, and it should not be replaced by an HMEF in a mechanical ventilation system.

Acknowledgments. None.

Financial support. No financial support was provided relevant to this article.

Conflicts of interest. All authors report no conflicts of interest relevant to this article.

\section{References}

1. Clinical management of severe acute respiratory infection (SARI) when COVID-19 disease is suspected interim guidance. World Health Orgnization website. https://www.who.int/docs/default-source/coronaviruse/ clinical-management-of-novel-cov.pdf. Published March 12, 2020. Accessed August 11, 2020.
2. Goh KJ, Wong J, Tien JC, et al. Preparing your intensive care unit for the COVID-19 pandemic: practical considerations and strategies. Crit Care 2020;24:215.

3. Halacli B, Kaya A, Topeli A. Critically-ill COVID-19 patient. Turk J Med Sci 2020;50:585-591.

4. Almstrand AC, Bake B, Ljungström E, et al. Effect of airway opening on production of exhaled particles. J Appl Physiol 2010;108:584-588.

5. Schwarz K, Biller H, Windt H, Koch W, Hohlfeld JM. 2010. Characterization of exhaled particles from the healthy human lung-a systematic analysis in relation to pulmonary function variables. J Aerosol Med Pulm Drug Deliv 2010;23:371-379.

6. Holmgren H, Gerth E, Ljungström E, et al. Effects of breath holding at low and high lung volumes on amount of exhaled particles. Respir Physiol Neurobiol 2013;185:228-234.

7. Wan GH, Wu CL, Chen YF, et al. Particle size concentration distribution and influences on exhaled breath particles in mechanically ventilated patients. PLoS One. 2014;9:e87088.

8. Ari A, Fink JB, Pilbeam S. Secondhand aerosol exposure during mechanical ventilation with and without expiratory filters: an in-vitro study. Indian $J$ Respir Care 2016;5:677-683.

9. Wilkes AR. Heat and moisture exchangers and breathing system filters: their use in anaesthesia and intensive care. Part 2-Practical use, including problems, and their use with paediatric patients. Anaesthesia 2011;66:40-51.

10. Li YC, Lin HL, Liao FC, et al. Potential risk for bacterial contamination in conventional reused ventilator systems and disposable closed ventilatorsuction systems. PLoS One 2018;13:e0194246.

\title{
Atypical COVID-19: Preventing transmission from unexpected cases
}

\author{
Angela Chow $\mathrm{PhD}^{1,2}$ (1), Htet Lin Htun $\mathrm{MPH}^{1}$ (D), Win Mar Kyaw MPH${ }^{1}$, Hou Ang MRCS ${ }^{3}$, Glenn Tan $\mathrm{FRCS}^{4}$, \\ Huei Nuo Tan MRCP ${ }^{5}$, Li Wearn Koh MRCP ${ }^{6}$, Bernard Yu-Hor Thong FRCP ${ }^{6}$ and Brenda Ang MPH ${ }^{2,7}$ \\ ${ }^{1}$ Department of Clinical Epidemiology, Office of Clinical Epidemiology, Analytics, and Knowledge (OCEAN), Tan Tock Seng Hospital, Singapore, ${ }^{2}$ Lee Kong Chian \\ School of Medicine, Nanyang Technological University, Singapore, ${ }^{3}$ Department of Emergency Medicine, Tan Tock Seng Hospital, Singapore, ${ }^{4}$ Department of \\ General Surgery, Tan Tock Seng Hospital, Singapore, ${ }^{5}$ Department of Geriatric Medicine, Tan Tock Seng Hospital, Singapore, ${ }^{6}$ Department of Rheumatology, \\ Allergy, and Immunology, Tan Tock Seng Hospital, Singapore and ${ }^{7}$ Department of Infectious Disease, Tan Tock Seng Hospital, Singapore
}

To the Editor-Much is still being discovered about coronavirus disease 2019 (COVID-19). Although originally described as viral pneumonia, reports of nonrespiratory manifestations of COVID-19 are increasing, including gastrointestinal, ocular, cardiac, and neurologic presentations. ${ }^{1-3}$ Hospitals restrict visitors with acute respiratory infections (ARIs), isolate and test all ARI patients for severe acute respiratory coronavirus virus 2 (SARS$\mathrm{CoV}-2$ ), and provide staff with full personal protective equipment when managing ARI patients. ${ }^{4}$ Concerns about how to titrate infection control measures for asymptomatic, presymptomatic, and atypical infections ${ }^{5}$ are heightened by fears of subsequent waves of COVID-19 from easing lockdowns. Transmission most likely occurs via droplets from infected individuals with respiratory symptoms, but it remains unclear whether SARS-CoV-2 is just as transmissible by patients who do not have respiratory symptoms.

Since January 23, 2020, the 1,600-bed Tan Tock Seng Hospital, co-located with the 330-bed National Centre for Infectious

\footnotetext{
Author for correspondence: Angela Chow, E-mail: angela_chow@ttsh.com.sg Cite this article: Chow A, et al. (2021). Atypical COVID-19: Preventing transmission from unexpected cases. Infection Control \& Hospital Epidemiology, 42: 1146-1148, https:// doi.org/10.1017/ice.2020.419
}

Diseases (NCID), has managed >9,000 COVID-19 patients. $^{6}$ Contact tracing was immediately performed for every COVID19 patient not managed at designated COVID-19 areas (fever zones) in the emergency department or clinic, or not pre-emptively admitted to an airborne infection isolation room (AIIR). In fever zones, all staff donned N95 respirators, gowns, gloves, and eye protection, while patients and visitors wore surgical masks. In nonfever zones, staff, patients, and visitors wore surgical masks and observed standard precautions.

Between January 23, 2020, and July 25, 2020, the hospital managed 5 COVID-19 patients without ARI symptoms who presented with gastrointestinal symptoms $(\mathrm{n}=2)$, upper-limb swelling $(\mathrm{n}=1)$, fever and muscle pain $(\mathrm{n}=1)$, and anxiety symptoms $(\mathrm{n}=1)$ (Table 1).

\section{Patient 1}

A 68-year-old woman presented to the emergency department non-fever zone on February 27, 2020, with a 2-week history of epigastric pain and nausea without fever or respiratory symptoms. She was admitted to a 5-bed cubicle in a general ward. On February 28, an abdominal/pelvic computed tomography scan revealed ground-

(c) 2020 by The Society for Healthcare Epidemiology of America. All rights reserved. This is an Open Access article, distributed under the terms of the Creative Commons Attribution licence (http://creativecommons.org/licenses/by/4.0/), which permits unrestricted re-use, distribution, and reproduction in any medium, provided the original work is properly cited. 
Table 1. Characteristics of Patients and the Exposed Contacts

\begin{tabular}{|c|c|c|c|c|c|}
\hline Characteristics & Patient 1 & Patient 2 & Patient 3 & Patient 4 & Patient 5 \\
\hline Age, $y$ & 68 & 80 & 55 & 90 & 42 \\
\hline Sex & Female & Male & Male & Female & Male \\
\hline Race & Chinese & Chinese & Chinese & Chinese & Chinese \\
\hline Pre-existing conditions & Nasal tip basal cell carcinoma & $\begin{array}{l}\text { Eosinophilic granulomatosis with polyangiitis, } \\
\text { gastric adenocarcinoma, chronic renal impairment, } \\
\text { active hepatitis B infection }\end{array}$ & None & $\begin{array}{l}\text { Alzheimer's disease, hypertension, } \\
\text { hyperlipidemia, diabetes mellitus, } \\
\text { paroxysmal atrial fibrillation }\end{array}$ & $\begin{array}{l}\text { Hyperlipidaemia, } \\
\text { gastroesophageal reflux }\end{array}$ \\
\hline Presenting symptoms & Nausea and abdominal pain & $\begin{array}{l}\text { Persistent middle-finger tenderness, and upper- } \\
\text { limb swelling }\end{array}$ & $\begin{array}{l}\text { Fever, muscle } \\
\text { pain, rash, and } \\
\text { nausea }\end{array}$ & $\begin{array}{l}\text { Vomiting, lethargy, and foul- } \\
\text { smelling urine }\end{array}$ & $\begin{array}{l}\text { Chest pain and } \\
\text { palpitations }\end{array}$ \\
\hline Admitting diagnosis & $\begin{array}{l}\text { Nausea likely secondary } \\
\text { to gall stones }\end{array}$ & Infective tenosynovitis & $\begin{array}{l}\text { Pulmonary } \\
\text { tuberculosis, } \\
\text { Dengue fever }\end{array}$ & Pneumonia, functional decline & Atypical chest pain \\
\hline Radiologic evidence of pneumonia & Yes & Yes & Yes & Yes & No \\
\hline $\begin{array}{l}\text { Managed at the outset at COVID-19 } \\
\text { designated areas in the ED/clinic }\end{array}$ & No & No & No & No & Yes \\
\hline $\begin{array}{l}\text { Time to isolation at COVID-19 } \\
\text { designated areas in ED/clinic, } \mathrm{h}\end{array}$ & NA & NA & 3 & 3 & NA \\
\hline $\begin{array}{l}\text { Admitted from ED/clinic directly to a } \\
\text { single room }\end{array}$ & No & No & Yes & Yes & $\begin{array}{l}\text { Yes, but subsequently } \\
\text { de-isolated }\end{array}$ \\
\hline Time in an open ward, $\mathrm{h}$ & 48 & 44 & NA & NA & 147 \\
\hline Length of hospitalization, $d$ & 8 & 13 & 11 & 6 & 9 \\
\hline Exposed contacts, no. & 92 & 33 & 35 & 20 & 67 \\
\hline \multicolumn{6}{|c|}{ Contacts with unprotected exposure, no. } \\
\hline Patients & 34 & 4 & 0 & 0 & 9 \\
\hline Visitors & 6 & 0 & 0 & 0 & 0 \\
\hline Caregivers & 2 & 0 & 0 & 0 & 0 \\
\hline Staff & 1 & 0 & 0 & 0 & 0 \\
\hline \multicolumn{6}{|l|}{ Contacts with protected exposure, no. ${ }^{\text {ab }}$} \\
\hline Patients & 0 & 0 & 0 & $1^{\mathrm{a}}$ & 0 \\
\hline Visitors & 0 & 0 & 0 & 0 & $10^{\mathrm{a}}$ \\
\hline Caregivers & 0 & 0 & 0 & 0 & 0 \\
\hline Staff & $\begin{array}{l}49 \\
\left(42^{\mathrm{a}} \text { and } 7^{\mathrm{b}}\right)\end{array}$ & $\begin{array}{l}29 \\
\left(28^{\mathrm{a}} \text { and } 1^{\mathrm{b}}\right)\end{array}$ & $\begin{array}{l}35 \\
\left(15^{\mathrm{a}} \text { and } 20^{\mathrm{b}}\right)\end{array}$ & $\begin{array}{l}19 \\
\left(13^{\mathrm{a}} \text { and } 6^{\mathrm{b}}\right)\end{array}$ & $48^{\mathrm{a}}$ \\
\hline $\begin{array}{l}\text { Symptomatic contacts screened for } \\
\text { SARS-CoV-2, no. }\end{array}$ & 11 & 3 & 5 & 0 & 0 \\
\hline $\begin{array}{l}\text { Asymptomatic contacts screened for } \\
\text { SARS-CoV-2, no. }\end{array}$ & 0 & 0 & 0 & 0 & 48 \\
\hline $\begin{array}{l}\text { Contacts confirmed with COVID-19, } \\
\text { no. }\end{array}$ & 0 & 0 & 0 & 0 & 0 \\
\hline
\end{tabular}


glass changes in her bilateral lower lungs. She was immediately transferred to a single-bed room. SARS-CoV-2 was detected on the second nasopharyngeal swab taken on March 1 . She was transferred to an AIIR, recovered uneventfully, and was discharged on March 5.

We identified 92 contacts (Table 1). Among them, 8 were inpatients who were moved to single-bed rooms. One staff member who had unprotected close contact developed ARI symptoms on March 1 and was admitted to the NCID, but 2 nasopharyngeal swabs collected 24 hours apart were negative for SARS-CoV-2. Moreover, 3 close patient contacts and a caregiver developed ARI symptoms, as well as another close patient contact whose chest $\mathrm{X}$-ray showed worsening of air-space changes. They were screened for SARS-CoV-2, and the virus was not detected in $\geq 2$ nasopharyngeal swabs taken 24 hours apart in these contacts. Also, 4 casual patient contacts and a staff member with protected exposure who became symptomatic also screened negative for SARS-CoV-2.

\section{Patient 2}

On March 20, 2020, an 80-year-old Chinese man with multiple comorbidities was admitted to a 5-bed cubicle from the rheumatology clinic for persistent left middle-finger tenderness and upper-limb swelling. A chest $\mathrm{x}$-ray showed resolving rightlower-zone pneumonia. He had a fever $\left(38.2^{\circ} \mathrm{C}\right)$ on March 22 and was transferred to a single-bed room. SARS-CoV-2 was detected on the nasal swab taken on the same day. He was transferred to an AIIR and was discharged on April 1 after recovering. He never developed respiratory symptoms.

We identified 33 contacts. All patient contacts remained asymptomatic, and 3 symptomatic staff contacts tested negative for SARS-CoV-2.

\section{Patient 3}

A 55-year-old Chinese man presented to the emergency department non-fever zone on March 24, 2020, with a 3-week history of intermittent fever, rash, nausea, and lethargy. The chest $\mathrm{x}$-ray suggested an atypical infection or pulmonary tuberculosis. A Dengue Duo test showed IgM and IgG positivity. He was admitted to a single-bed room. SARS-CoV-2 was detected in the nasal swab taken on the same day, and he was transferred to an AIIR. Tuberculosis was ruled out by negative acid-fast bacilli smears and cultures. He did not develop any respiratory symptoms and was discharged on April 3 after recovering.

We identified 35 contacts, all staff. Among them, 5 developed symptoms but tested negative for SARS-CoV-2.

\section{Patient 4}

On April 20, 2020, a 90-year-old Chinese-woman with multiple comorbidities presented to the emergency department non-fever zone with a 1-day history of vomiting, lethargy, and foul-smelling urine. She had no fever or respiratory symptoms, but a chest $\mathrm{x}$-ray revealed left-lower-zone air-space opacities and pleural effusion. She was admitted to a single-bed room. SARS-CoV-2 was detected on the second sample. She was immediately transferred to an AIIR and was discharged on April 25 after recovering. All 20 contacts remained asymptomatic until 14 days after exposure.

\section{Patient 5}

A 42-year-old Chinese man, a resident of a dormitory with COVID-19 transmission, presented with chest pain and palpitations on June 16, 2020. He was admitted to an AIIR but was transferred to a 5-bed cubicle for treatment of an anxiety disorder after testing negative for SARS-CoV-2. The day after his discharge on June 22, he was screened for SARS-CoV-2 in preparation for China travel and tested positive.

Of 3 in-hospital patient contacts, 1 was detected with SARS$\mathrm{CoV}-2$ on June 25 . This patient had been admitted for congestive cardiac failure and suspected pneumonia. This patient contact and patient 5 had reactive SARS-CoV-2 serological tests taken on June 27 and 28, respectively; thus, it was improbable that the patient contact acquired COVID-19 from patient 5 while receiving care in the same cubicle.

In conclusion, we have reported 5 patients not initially suspected with COVID-19 and thus not managed at COVID19-designated areas or AIIRs. In total, 247 contacts were identified from the hospital's patient and visitor registration systems, staff rosters, electronic medical records, and closed-circuit television. Also, 56 contacts with unprotected exposure were quarantined or placed under phone surveillance for 14 days after exposure. Finally, 19 symptomatic contacts and 48 asymptomatic staff contacts were tested for SARS-CoV-2; none were positive for the virus.

Because the same vigilance for ARI patients cannot realistically be implemented for the smaller proportion of patients with atypical symptoms, the following measures are crucial for preventing nosocomial transmission of SARS-CoV-2: a robust hospital system with risk-based personal protective equipment, staff sickness surveillance, ${ }^{7}$ and rapid identification of COVID-19 patients with immediate contact tracing and management.

Acknowledgments. We would like to thank the staff members of the emergency department, clinics, general wards, Department of Clinical Epidemiology, Department of Infection Prevention and Control, and Occupational Health Clinic, whose efforts in contact tracing and management prevented any nosocomial transmission.

Financial support. No financial support was provided relevant to this article.

Conflicts of interest. All authors report no conflicts of interest relevant to this article.

\section{References}

1. Edirappuli SD, Venkatesh A. Atypical symptoms in COVID-19: the many guises of a common culprit. BMJ 2020;369:m1375.

2. Abobaker A, Raba AA, Alzwi A. Extrapulmonary and atypical clinical presentations of COVID-19. J Med Virol 2020. doi 10.1002/jmv.26157.

3. Small CN, Beatty NL. Atypical features of COVID-19: a literature review. $J$ Clin Outcomes Manag 2020;27:131-134.

4. Klompas M. Coronavirus disease 2019 (COVID-19): protecting hospitals from the invisible. Ann Intern Med 2020;172:619-620.

5. Arons MM, Hatfield KM, Reddy SC, et al. Presymptomatic SARS-CoV-2 infections and transmission in a skilled nursing facility. $N$ Engl J Med 2020;382:2081-2090.

6. Soh EF. TTSH, NCID battle plan passes test. Business Times website. https:// www.businesstimes.com.sg/leadership-management/ttsh-ncid-battleplan-passes-test. Published June 12, 2020. Accessed July 15, 2020.

7. Htun HL, Lim DW, Kyaw WM, et al. Responding to the COVID-19 outbreak in Singapore: staff protection and staff temperature and sickness surveillance systems. Clin Infect Dis 2020. doi 10.1093/cid/ciaa468. 